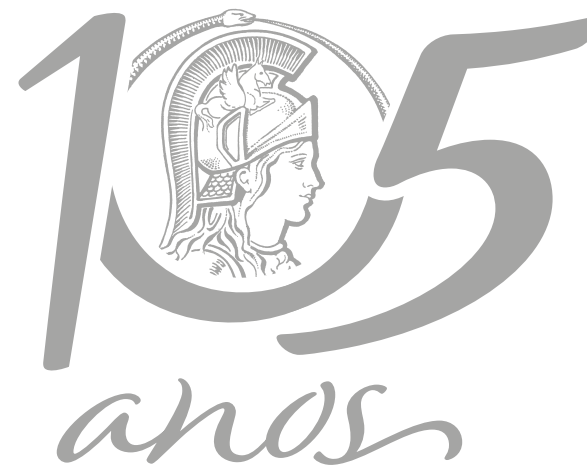

$1916 \cdot 2021$

EDITORIAL NOTE

\title{
New scientific fields in the Annals of the Brazilian Academy of Sciences
}

\author{
ALEXANDER W.A. KELLNER
}

The Annals of the Brazilian Academy of Sciences $(A A B C)$ is the only multidisciplinary journal of Brazil that publishes papers in almost any scientific field. From articles monitoring air quality (Ventura et al. 2019), environmental risks caused by pesticides (e.g., Bueno \& Cunha 2019), and Kumaraswamy distributions (Cribari-Neto \& Santos 2019), to studies on natural compounds that might be used in specific health treatments (e.g., Soares et al. 2019), new fossil occurrences (e.g., Del Fueyo et al. 2019), and articles dealing with various aspects of social sciences (e.g., Braga et al. 2020), making the $A A B C$ the only periodical edited in the country with such a broad scope.

Over the years, the number of manuscript submissions has increased at a very high rate, with two areas standing out in the last decade: Agrarian and Biological Sciences (Kellner 2020a, b). The number of manuscripts submitted for Agrarian Sciences increased from 53 in 2011 to 275 in 2016, and to the record-breaking figure of 584 in 2020 (Table I). Biological Sciences, the area that traditionally has the highest submitting rate in the AABC, received 164 manuscripts in 2011, 274 in 2016 and 556 in 2020 (Table I).

Regarding Biological Sciences, there is a general trend towards an increase in absolute terms of submissions. However, compared to other areas of the journal, in the last decade there is a gradual decline in the proportion of submissions concerning this scientific field received by $A A B C$ (Table $1 \mathrm{I}$ ). This is exactly the opposite of what is observed in Agrarian Sciences, where there has been a constant increase both in absolute numbers and in the proportion of submissions (Table II). Since 2016, the submissions in Agrarian Sciences have rivaled and even supplanted that of Biological Sciences (Table I). The reason for this significant change, which ends up influencing the journal output, seems to be related to the Qualis system, which is fundamental in the assessment of scientific production in Brazil. Despite the efforts to internationalize the $A A B C$, there is still a great predominance of submissions from the country and the influence of Qualisites (Kellner 2017) becomes apparent, particularly comparing the development of these two areas in the journal.

In any case, Biological and Agrarian Sciences are responsible for more than half of the articles published by the AABC (Table II). In order to assess the effective contribution of these papers to the journal's Impact Factor, some brief comparisons in relation to the publication considered by the Journal Citation Reports (Clarivate 2020) were made (Kellner 2020a, b), focusing on articles published during 2018 (AABC-90). The results revealed that for the 
Table I. Manuscripts submitted, rejected, and published in Biological, Agrarian and Earth Sciences in the last decade in the Annals of the Brazilian Academy of Sciences.

\begin{tabular}{|c|c|c|c|c|}
\hline & BiSci & AgSci & EaSci & AABC - tot* \\
\hline 2011 - sub & 164 & 53 & 33 & 317 \\
\hline 2011 - rej & 108 & 36 & 24 & 202 \\
\hline $2011-$ pub & 28 & 12 & 44 & 112 \\
\hline 2012 - sub & 159 & 55 & 28 & 301 \\
\hline 2012 - rej & 112 & 45 & 10 & 196 \\
\hline $2012-$ pub & 50 & 10 & 23 & 104 \\
\hline $2013-$ sub & 197 & 111 & 43 & 470 \\
\hline 2013 - rej & 113 & 65 & 16 & 264 \\
\hline $2013-p u b$ & 75 & 17 & 14 & 140 \\
\hline $2014-$ sub & 304 & 123 & 39 & 641 \\
\hline 2014 - rej & 187 & 81 & 21 & 391 \\
\hline $2014-p u b$ & 82 & 32 & 32 & 175 \\
\hline 2015 - sub & 355 & 195 & 57 & 827 \\
\hline 2015 - rej & 277 & 129 & 31 & 590 \\
\hline $2015-$ pub & 77 & 25 & 20 & 185 \\
\hline $2016-$ sub & 274 & 275 & 53 & 830 \\
\hline 2016 - rej & 194 & 202 & 26 & 581 \\
\hline 2016 - pub & 91 & 25 & 24 & 200 \\
\hline 2017 - sub & 293 & 252 & 72 & 950 \\
\hline 2017 - rej & 192 & 192 & 35 & 639 \\
\hline 2017 - pub & 95 & 59 & 26 & 250 \\
\hline 2018 - sub & 397 & 390 & 98 & 1281 \\
\hline 2018 - rej & 210 & 264 & 54 & 797 \\
\hline $2018-p u b$ & 65 & 122 & 28 & 300 \\
\hline 2019 - sub & 482 & 485 & 83 & 1512 \\
\hline 2019 - rej & 226 & 363 & 55 & 957 \\
\hline $2019-p u b$ & 123 & 45 & 35 & 301 \\
\hline $2020-s u b$ & 556 & 584 & 112 & 1880 \\
\hline 2020 - rej & 374 & 499 & 69 & 1399 \\
\hline $2020-p u b$ & 119 & 76 & 18 & 350 \\
\hline
\end{tabular}

Abbreviations: AgSci - Agrarian Sciences, BiSci - Biological Sciences, EaSci - Earth Sciences; pub - published, rej - rejected, sub - submitted, tot - total number. *Excluding editorials and letters. The numbers reflect the manuscripts that were submitted, rejected, and published in the corresponding year.
Table II. Proportions of submitted and published manuscripts in Biological and Agrarian Sciences in relation to the total number of manuscripts submitted and published in the last decade in the Annals of the Brazilian Academy of Sciences.

\begin{tabular}{|c|c|c|c|}
\hline Year & $\begin{array}{c}\text { BiSci/ } \\
\text { AABC Tot* } \\
(\%)\end{array}$ & $\begin{array}{c}\text { AgSci/ } \\
\text { AABC Tot* } \\
(\%)\end{array}$ & $\begin{array}{c}\text { EaSci/ } \\
\text { AABC Tot* } \\
(\%)\end{array}$ \\
\hline 2011 - sub & 51.74 & 16.72 & 10.41 \\
\hline $2011-$ pub & 25.00 & 10.71 & 39.29 \\
\hline 2012 - sub & 52.82 & 18.27 & 9.30 \\
\hline $2012-p u b$ & 48.77 & 9.62 & 22.12 \\
\hline 2013 - sub & 41.91 & 23.62 & 9.15 \\
\hline 2013 - pub & 53.57 & 12.14 & 10.00 \\
\hline 2014 - sub & 47.43 & 19.19 & 6.08 \\
\hline $2014-p u b$ & 46.86 & 18.29 & 18.29 \\
\hline 2015 - sub & 42.93 & 23.58 & 6.89 \\
\hline 2015 - pub & 41.62 & 13.51 & 10.81 \\
\hline 2016 - sub & 33.01 & 33.13 & 6.39 \\
\hline 2016 - pub & 45.50 & 12.50 & 12.00 \\
\hline 2017 - sub & 30.84 & 26.57 & 7.58 \\
\hline 2017 - pub & 38.00 & 23.60 & 10.40 \\
\hline 2018 - sub & 30.99 & 30.44 & 7.65 \\
\hline $2018-$ pub & 21.67 & 40.67 & 9.33 \\
\hline 2019 - sub & 31.88 & 32.08 & 5.49 \\
\hline $2019-$ pub & 40.86 & 14.95 & 11.63 \\
\hline $2020-$ sub & 29.57 & 31.06 & 5.96 \\
\hline $2020-$ pub & 34.00 & 21.72 & 5.14 \\
\hline
\end{tabular}

Abbreviations: AgSci - Agrarian Sciences, BiSci - Biological Sciences, EaSci - Earth Sciences; pub - published, sub submitted, tot - total number. *Excluding editorials and letters. Proportions based on Table I.

AABC 2019 IF, the actual contribution of both areas was not very impressive (Kellner 2020a, b, c, d). These succinct analyzes also show that better manuscript selection (a topic that triggers heated debates) could increase the journal's overall bibliometric indexes (Kellner 2020d).

Another action that $A A B C$ decided to carry out and which was implemented this year (2021), was to divide these two areas. Biological 
Sciences was replaced by Cellular and Molecular Biology (CeMoBio), Microbiology (Mcbio), and Ecosystems (Ecosy), while Agrarian Sciences was replaced by Animal Science (AnSci), Crop Science (CrSci), Soil Science (SoiSci), and Forestry Science (FoSci). The main purpose of these changes is to call attention of researchers working in these more specific areas to consider the $A A B C$ for the publication of their results.

At the same time and for the same reasons, Earth Sciences were separated into Geosciences (Geosci) and Paleontology (Paleo). The articles from these areas published in the AABC-90 contributed significantly to the AABC 2019 IF (Kellner 2020c) and, by drawing attention to these fields, this journal hopes to obtain more relevant submissions. Despite increasing in total numbers, the submissions in Earth Sciences have been decreasing proportionally in the last decade (Table II). In the coming years, we will see if this strategy will be successful and if it should be applied to other areas as well (e.g., Health Sciences).

\section{REFERENCES}

BRAGA AC, RESENDE LMM \& PONTES J. 2020. Proposal of a theoretical model to identify organizational decline. An Acad Bras Cienc 92: e20180455. DOI. 10.1590/0001 3765202020180455.

BUENO MR \& CUNHA PAR. 2019. Environmental risk for aquatic and terrestrial organisms associated with drift from pesticides used in soybean crops. An Acad Bras Cienc 91: e20181245. DOI 10.1590/0001-3765202020181245.

CLARIVATE. 2020. 2019 Journal Impact Factor. Journal Citation Reports.

CRIBARI-NETO F \& SANTOS J. 2019. Inflated Kumaraswamy distributions. An Acad Bras Cienc 91: e20180955. DOI 10.1590/10.1590/0001-3765201920180955.

DEL FUEYO GM, GNAEDINGER SC, LAFUENTE DIAZ MA AND CARRIZO MA. 2019. Permineralized conifer-like leaves from the Jurassic of Patagonia (Argentina) and its paleoenvironmental implications. An Acad Bras Cienc 91: e20180363. DOI 10.1590/0001-3765201920180363.
KELLNER AWA. 2017. The Qualis system: a perspective from a multidisciplinary journal. An Acad Bras Cienc 89: 13391342. DOI 10.1590/0001-37652017893.

KELLNER AWA. 2020a. Development of Agrarian Sciences at the $A A B C$ with comments on impact and performance evaluations. An Acad Bras Cienc 92: e202092S1. DOI 10.1590/00013765202092S1.

KELLNER AWA. 2020b. Development of Biological Sciences at the AABC. An Acad Bras Cienc 92: e202092S2. DOI 10.1590/0001-3765202092S2.

KELLNER AWA. 2020c. Impact and performances of different scientific fields at the AABC. An Acad Bras Cienc 92: e2020923. DOI 10.1590/0001-37652020923.

KELLNER AWA. 2020d. A brief summary of the impact and performance of different scientific fields at the AABC. An Acad Bras Cienc 92: e2020924. DOI 10.1590/0001-37652020924

SOARES JM, FARIA BM, ASCARI LM, ALVES-LEON SV, SOUZA JM, SOARES AG, CORDEIRO Y \& ROMÃO LF. 2019. DiOsmin induces caspase-dependent apoptosis in human glioblastoma cells. An Acad Bras Cienc 91: e20191031. DOI 10.1590/0001-3765201920191031.

VENTURA LMB, RAMOS MB, SANTOS JO \& GIODA A. 2019. Monitoring of air quality before the Olympic Games Rio 2016. An Acad Bras Cienc 91: e20170984. DOI 10.1590/0001-3765201920170984.

\section{How to cite}

KELLNER AWA. 2021. New scientific fields in the Annals of the Brazilian Academy of Sciences. An Acad Bras Cienc 93: e202193s3. DOI 10.1590/0001-37652021202193s3.

\section{ALEXANDER W.A. KELLNER}

https://orcid.org/0000-0001-7174-9447

Universidade Federal do Rio de Janeiro, Museu Nacional, Laboratório de Sistemática e Tafonomia de Vertebrados Fósseis, Departamento de Geologia e Paleontologia, Quinta da Boa Vista, s/n, São Cristóvão, 20940-040 Rio de Janeiro, RJ, Brazil

E-mail:kellner@mn.ufrj.br

\section{(cc) BY}

